\title{
Case study of polychlorinated naphthalene emissions and factors influencing emission variations in secondary aluminum production
}

\author{
Xiaoxu Jiang, Guorui Liu*, Mei Wang, Wenbin Liu, Chen Tang, Li Li, Minghui Zheng* \\ State Key Laboratory of Environmental Chemistry and Ecotoxicology, Research Center for Eco-Environmental Sciences, Chinese Academy of Sciences, P.O. \\ Box 2871, Beijing 100085, China
}

\section{H I G H L I G H T S}

- Variations in PCN emissions from different smelting stages were observed.

- Factors influencing PCN emission levels and profiles were identified.

- Addition of chloride additives possibly promote PCN formations.

- Emission factors for gaseous and various solid discharges were derived.

- This study is helpful for developing better control strategies for PCN reduction.

\section{A R T I C L E I N F O}

\section{Article history:}

Received 8 October 2014

Received in revised form

17 December 2014

Accepted 4 January 2015

Available online 6 January 2015

\section{Keywords:}

Secondary aluminum production

Smelting stages

Polychlorinated naphthalene

Solid residues

Chloride additives

\section{G R A P H I C A L A B S T R A C T}

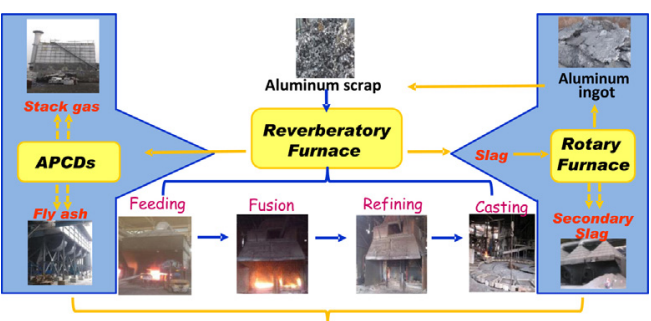

PCN Emission from Secondary Aluminum Smelting Process

\begin{abstract}
A B S T R A C T
Secondary aluminum production has been recognized as an important source of polychlorinated naphthalenes (PCNs). Large variations in PCN emissions as the smelting process proceeds have not been determined. In this study, solid and gaseous discharges, including fly ash, slag, and stack gas samples collected from four secondary smelting plants during different smelting stages were analyzed for PCNs. The average emission factor of $\sum_{1-8} \mathrm{PCNs}$ to air was calculated to be $17.4 \mathrm{mg} \mathrm{t}^{-1}$, with a range of 4.3-29.5 $\mathrm{mg} \mathrm{t}^{-1}$. The average emission factors of $\sum_{1-8} \mathrm{PCNs}$ from fly ash and slag were $55.5 \mathrm{ng} \mathrm{t}^{-1}$ and $0.13 \mathrm{ng} \mathrm{t}^{-1}$, respectively. The derived emission factors may enable a more accurate estimation of annual emissions and a more comprehensive knowledge of the distribution of PCNs emitted from secondary aluminum production. The emission levels and characteristics of PCNs during different smelting stages were compared. Possible factors, including the organic impurities from aluminum scrap, fuel, and chloride additives, which could contribute to variations in PCN emissions and characteristics were discussed. These results may provide useful information for developing better control strategies for reducing PCN emissions in secondary aluminum production.
\end{abstract}

(C) 2015 Elsevier B.V. All rights reserved.

\section{Introduction}

Polychlorinated naphthalenes (PCNs) are persistent organic pollutants (POPs), and are ubiquitous in environmental matrices and

\footnotetext{
* Corresponding authors. Tel.: +861062849172.

E-mail addresses: grliu@rcees.ac.cn (G. Liu), zhengmh@rcees.ac.cn (M. Zheng).
}

biota [1-3]. It has recently been proposed that PCNs be included in Annexes A, B, and/or C of the Stockholm Convention on Persistent Organic Pollutants. The main sources of PCNs are the historical manufacture of technical PCN mixtures, impurities in commercial polychlorinated biphenyl mixtures and other chemicals, and unintentional production and release from industrial thermal processes [4-6]. The production and use of technical PCNs was banned in the United States and Europe in the 1980s. Currently, the major contrib- 
utors to PCN emissions are thermal-related industries, including waste incineration, coking processes, and metallurgical processes such as secondary nonferrous smelting, iron ore sintering, and steelmaking using electric arc furnaces [7-11]. However, investigations on developing control measures aimed at reducing PCN emissions from these industrial processes are still scarce.

The decreasing costs and increasing availability of aluminum products for use in food packaging, construction, transportation, electrical applications, consumer durables, machinery and industry use forecast a growing disposal burden of aluminum scrap. Secondary aluminum smelting can dispose of aluminum scrap in an economical and recyclable way, because aluminum scrap can be recycled without any loss of quality and the production of secondary aluminum requires only $5-20 \%$ of the energy required for the production of primary aluminum from bauxite [12]. Under these circumstances, the activity rate for global secondary aluminum production has been significant in recent years. China is the largest aluminum-producing country, accounts for $\sim 34 \%$ of global aluminum production, with a secondary aluminum production of $\sim 3000000 \mathrm{ta}^{-1}$ during 2011-2013 [13]. There are large discrepancies in the scales and technologies for secondary aluminum production in China; therefore, an investigation of PCN emissions from the Chinese secondary aluminum industry would facilitate an evaluation of the release of PCNs from secondary aluminum smelting processes on a global scale.

In our previous study, atmospheric emission factors and total PCN emissions from secondary aluminum production in China were investigated [14]. Large variations in PCN concentrations were observed, from $98.9-2245 \mathrm{ng} \mathrm{m}^{-3}$, from secondary aluminum production in China [14]. However, the reasons for the large variations in PCN emission concentrations have not been considered in previous research. PCN emissions and characteristics at different smelting stages may differ depending on the operating conditions and the feedstock composition during secondary aluminum smelting process. Studies conducted to investigate PCN emissions and characteristics at different smelting stages could; therefore, facilitate understanding of the formation mechanisms of PCNs. PCNs can bind to particles and also partition into the gas phase because of their semi-volatility $[9,14,15]$. However, the field data from most previous investigations focusing on gaseous emissions are unavailable for assessing the integrated emission of PCNs in all discharges. Furthermore, disregarding the solid residues that are produced in the system would result in an insufficient risk assessment and inappropriate disposal, which could cause potential risks to the environment and involved workers.

In this study, fly ash from a bag filter, slag from smelting of aluminum scrap, secondary slag from secondary rotary smelting of slag, and stack gas at different smelting stages were collected from four secondary aluminum smelting plants. To the best of our knowledge, investigations of the presence of PCNs in various discharges from secondary aluminum smelting processes or other metallurgical processes are scarce. The aim was to obtain a comprehensive knowledge of the overall $\mathrm{PCN}$ emission distribution in secondary aluminum smelting processes. The results from this study could provide useful information for obtaining comprehensive information on PCN emission distributions, understanding PCN emission mechanisms, and developing better control strategies for PCN emissions in secondary aluminum production.

\section{Experimental}

\subsection{Plant information}

Four typical plants in China (denoted by AL1-AL4) were selected, based on their different operating technologies, including furnace type, fuel, and raw materials. In the secondary production of aluminum, scrap can be melted in gas- or oil-fired reverberatory furnaces in all the plants investigated. The reverberatory furnace production is the traditional technology for secondary aluminum production in China because of its high volumetric processing rate, and low operating and maintenance costs. Light oil, natural gas, or coal gas was used as fuel to melt the raw materials. The raw materials, which are a complex combination of all types of collected aluminum scraps, are loaded into melting furnaces. A significant amount of raw materials, including foils, extrusions, turnings, and borings from metal manufacturing processes, are defined as "clean aluminum scrap" in this study. Typical sources of raw materials also include "dirty aluminum scrap" from the recycling of consumer products. The air pollution control devices used in all the plants investigated were bag filters. Bag filters, which are bag-shaped dust collectors made of fabric filters, are widely used as air pollution control devices (APCDs) in industrial plants for capturing entrained particulate matter from flue gases. The four plants included the largest secondary aluminum plant in Asia, which uses advanced technologies, and three smaller-scale plants, which use traditional technologies; these plants are distributed across China.

\subsection{Sample collection}

The samples for this study were collected in June 2013. The stack gas samples were collected using an automatic isokinetic sampling system. The sampling point was set downstream of all air pollution control devices. Briefly, the sampling train consisted of a heated probe, a filter box equipped with a silica glass microfiber thimble (25 mm i.d., $90 \mathrm{~mm}$ length; Whatman International Ltd., Whatman, UK), a water-cooled Amberlite XAD-2 adsorbent trap (Supleco International Ltd., Varina, USA), an Isotack Basic (TCR Tecora, Italy) pump and an Isofrost cooler (TCR Tecora, Italy). Particles in the stack gas were trapped by the silica glass microfiber thimble. Gases were cooled in a condensing system and then adsorbed in a trap with Amberlite XAD-2 resin. Four distinct smelting stages are involved in secondary aluminum smelting: feeding (FD), fusion (FS), refining (RF), and casting (CS). Aluminum scrap is usually smelted and refined in a reverberatory furnace. Once smelted, the flux, which usually consists of $\mathrm{NaCl}$ and $\mathrm{KCl}$, is added to remove some impurities from the molten aluminum [16-18]. In this study, 15 stack gas samples and eight residue samples were collected. In plant AL1, three stack gas samples were collected during the FD, FS, and RF stages, and in AL2, three stack gas samples were collected in the FD, FS, and CS stages, based on the limited scope for sampling in the plants. Three mixed gas samples were collected from AL3 and four mixed gas samples were collected from AL4, because several furnaces were in operation simultaneously at these plants. Fly ash samples were collected simultaneously from the bag filter outlets at all four plants. Slag samples were collected from the reverberatory furnace before the slag was shifted to the rotary furnace for secondary smelting at plants AL1 and AL2. Secondary slag samples were collected at the bottom of the rotary furnace, after secondary smelting was completed, at plants AL1 and AL2. All solid samples were homogenized before analysis. Basic information on the secondary aluminum smelting plants is shown in Table 1.

\subsection{Analytical methods}

The stack gas samples and solid residue samples ( $2 \mathrm{~g})$ were pretreated and analyzed for PCNs by isotope dilution high-resolution gas chromatography and high-resolution mass spectrometry $[9,19]$. The stack gas samples and residues were spiked with a mixture of ${ }^{13} \mathrm{C}_{10}$-labeled PCN internal standards (ECN-5102, tetrato octa-CN mixture comprising ${ }^{13} \mathrm{C}_{10}-\mathrm{CN}-27,-42,-52,-67,-73$, and -75 , Cambridge Isotope Laboratories, Andover, MA, USA). The stack gas samples were directly Soxhlet extracted with toluene 
Table 1

Basic information on the secondary aluminum plants investigated.

\begin{tabular}{|c|c|c|c|c|c|c|}
\hline Plant denotation & $\begin{array}{l}\text { Reverberatory } \\
\text { furnace }\end{array}$ & $\begin{array}{l}\text { Furnace in } \\
\text { use }\end{array}$ & Fuel & Raw material & $\begin{array}{l}\text { Annual capacity } \\
\left(10^{3} \mathrm{t}_{\text {year }}{ }^{-1}\right)\end{array}$ & Sampling stages \\
\hline AL1 & $\begin{array}{l}\text { Melting- } \\
\text { converting } \\
\text { furnace }\end{array}$ & 1 & Light oil & Dirty scrap & 14.6 & Feeding/fusion/refining \\
\hline AL2 & Single furnace & 4 & Natural gas & $\begin{array}{l}\text { Clean scrap } \\
(80 \%)+\text { dirty } \\
\text { scrap }(20 \%)\end{array}$ & 28.0 & Mixing \\
\hline AL3 & Single furnace & 1 & Coal gas & Clean scrap & 9.0 & Feeding/fusion/casting \\
\hline AL4 & $\begin{array}{l}\text { Melting- } \\
\text { converting } \\
\text { furnace }\end{array}$ & 7 & Natural gas & Dirty scrap & 116.8 & Mixing \\
\hline
\end{tabular}

( $250 \mathrm{~mL}$ ) for about $24 \mathrm{~h}$. The residue samples, i.e., fly ash, slag, and secondary slag, were pretreated by digestion in $1 \mathrm{~mol} \mathrm{~L}^{-1} \mathrm{HCl}$. After digestion, the residue samples were freeze-dried to remove water. The pretreated solid residue were then Soxhlet extracted with toluene $(250 \mathrm{~mL})$ for about $24 \mathrm{~h}$. After extraction, the extracts from solid residue samples and stack gas samples were cleaned by passing them through a multilayer silica-gel column (from top to bottom: anhydrous sodium sulfate, $1 \mathrm{~g}$ of silica gel, $15 \mathrm{~g}$ of $44 \%$ silica gel-sulfuric acid, $1 \mathrm{~g}$ of silica gel, $4 \mathrm{~g}$ of $33 \%$ silica gel-sodium hydroxide, and $1 \mathrm{~g}$ of silica gel) and then an activated carbon column. The cleaned extracts were concentrated by rotatory evaporation and then under a gentle stream of nitrogen to about $20 \mu \mathrm{L}$. Prior to injection, ${ }^{13} \mathrm{C}_{10}$-labeled PCNs with known standard concentrations (ECN-5260: ${ }^{13} \mathrm{C}_{10}-\mathrm{CN}-64$, Cambridge Isotope Laboratories, Andover, MA, USA) were added to the concentrated effluents. The 75 PCN congeners were analyzed using a gas chromatograph equipped with a DB-5 MS fused-silica column $(60 \mathrm{~m} \times 0.25 \mathrm{~mm}$ i.d. $\times 0.25 \mu \mathrm{m}$, J\&W, Agilent Technologies Inc., CA, USA) coupled with a DFS mass spectrometer (Thermo Fisher Scientific, NH, USA) in selective ion monitoring mode. The mass spectrometer was tuned and operated at a resolution of approximately 10000 with an electron ionization energy of $45 \mathrm{eV}$. The source temperature was $270^{\circ} \mathrm{C}$. The column temperature was initially $80^{\circ} \mathrm{C}$ (for $2 \mathrm{~min}$ ), and was increased to $180^{\circ} \mathrm{C}$ (for $1 \mathrm{~min}$ ) at $20^{\circ} \mathrm{C} \mathrm{min}^{-1}, 280^{\circ} \mathrm{C}$ at

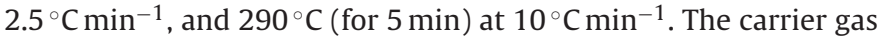
was helium with a flow rate of $1 \mathrm{~mL} \mathrm{~min}^{-1}$. Peaks were identified based on comparison of the retention times with those of available individual standards and ion ratios, and considering the elution order on the DB- 5 column. The recoveries of ${ }^{13} C_{10}$-labeled PCN congeners relative to the labeled injection standard were $35-118 \%$ for all matrices. Blank tests were carried out every three samples.

\section{Results and discussion}

\subsection{PCN emissions in major discharges}

The concentrations of $\Sigma_{1-8}$ PCNs in the stack gas samples from the four investigated plants were converted to dry standard conditions ( $273 \mathrm{~K}$ and $101.3 \mathrm{kPa}$ ). PCNs have been proven to have dioxin-like toxic activities [20,21], and the toxic equivalent factors (TEFs) of several PCN congeners relative to $2,3,7,8$ tetrachlorodibenzo- $p$-dioxin have been studied [20-25]. In this study, the TEFs of several PCN congeners, summarized by Noma et al. [26], were adopted in the calculation of the $\Sigma_{1-8}$ PCN toxic equivalents (TEQs). The mass concentrations and TEQ concentrations of $\Sigma$ PCN in all the investigated discharges are listed in Table 2. There were large variations in the PCN concentrations from the plants investigated, which is consistent with our previous study [9]. The mass concentrations and TEQs of the PCNs in the stack gas samples were comparable to those obtained for other secondary aluminum smelting plants in China in our previous study [9].
The PCN emission factors can be considered to be the release rates of PCNs relative to the production output from secondary aluminum smelting plants. The mass concentration and TEQ concentration emission factors of various types of discharges, including stack gas and solid residues (i.e., fly ash, slag and secondary slag), for the investigated secondary aluminum smelting plants were derived from Eqs. (1) and (2), respectively [9,19,27].

Stack gas emission factor $=\frac{(\text { concentration } \times \text { flow rate of stack gas })}{\text { output rate }}$

Soild residue emission factor=concentration

$\times$ amount of solid residue per ton of product

The calculated mass emission factors and TEQ emission factors of $\Sigma$ PCNs for all discharges are shown in Table 2. The mass emission factors of $\Sigma$ PCNs from the different plants varied by as much as two orders of magnitude. Furthermore, the emission factors of the PCNs for stack gas, fly ash, and slag were compared within each investigated plant to understand the distribution in each discharge in secondary aluminum production. Most PCNs (>99.9\%) were distributed in the gas phase. The order of the emission factors for the investigated emission discharges was stack gas $>$ fly ash $>$ slag. This gas-solid partition information suggests that the control of gaseous emissions in secondary aluminum smelting processes should be prioritized. For example, the results suggest that the APCDs in these plants cannot effectively remove PCN air emissions through bag filters in these secondary aluminum plants. The removal efficiency of PCNs by APCDs should therefore be improved. Among the solid residues, the fly ash PCN emissions exceeded those of the slag. The slag and secondary slag showed comparable levels of remaining PCNs. Fly ash was the major effluent in the solid-phase emission of PCNs in the secondary aluminum smelting process. An insignificant reduction in toxicity was achieved by rotary smelting, and slag melting showed inadequate PCN removal efficiency. The disposal of fly ash and slag still needs to be handled with care to avoid potential risks to the environment and involved workers.

The raw materials, operating technologies, and fuel types are important factors that may influence unintentional POP emissions during industrial thermal processes [29-35]. The possible influence of raw materials, fuel types, and plant scales on PCN concentrations in stack gas and fly ash samples were preliminarily investigated in this study. No significant correlations were observed between the plant scale and emission levels for all the discharges. The PCN emission levels were evaluated based on the types of fuel and raw materials. The average TEQ concentration of PCNs in stack gas was $38.2 \mathrm{pg}$ TEQ $\mathrm{m}^{-3}$ for plants using dirty scrap (AL1 and AL4); this was higher than the concentration for the plant using mixed scrap ( $20 \%$ dirty scrap and $80 \%$ clean scrap) as raw materials, which had a 
Table 2

Concentrations and emission factors of PCNs in four types of discharges.

\begin{tabular}{|c|c|c|c|c|c|c|}
\hline Release route & Plant denotation & $\begin{array}{l}\text { Annual output } \\
\left(10^{6} \mathrm{~m}^{3} \text { year }^{-1} \text { or }\right. \\
\text { t year }\end{array}$ & $\begin{array}{l}\text { Mass } \\
\text { concentration } \\
\left(\mathrm{ng} \mathrm{g}^{-1} \text { or }\right. \\
\left.\mathrm{ng} \mathrm{m}^{-3}\right)\end{array}$ & $\begin{array}{l}\text { TEQ } \\
\text { concentration } \\
\left(\mathrm{pg} \mathrm{TEQ} \mathrm{g}^{-1} \text { or pg }\right. \\
\text { TEQ } \mathrm{m}^{-3} \text { ) }\end{array}$ & $\begin{array}{l}\text { Mass emission } \\
\text { factor }\left(\mathrm{mg} \mathrm{t}^{-1}\right)\end{array}$ & $\begin{array}{l}\text { TEQ emission } \\
\text { factor }(\mu \mathrm{g} \text { TEQ } \\
\left.\mathrm{t}^{-1}\right)\end{array}$ \\
\hline \multirow[t]{4}{*}{ Stack gas } & AL1 & 1168 & 363 & 69.8 & 29.1 & 5.6 \\
\hline & AL2 & 340 & 559 & 9.5 & 6.8 & 0.12 \\
\hline & AL3 & 656 & 59.5 & 2.1 & 4.3 & 0.16 \\
\hline & AL4 & 5424 & 635 & 6.5 & 29.5 & 0.30 \\
\hline \multirow[t]{4}{*}{ Fly ash } & AL1 & 660 & 969 & 1087 & $4.4 \times 10^{-5}$ & $4.9 \times 10^{-5}$ \\
\hline & AL2 & 1400 & 372 & 87.6 & $1.9 \times 10^{-7}$ & $4.4 \times 10^{-6}$ \\
\hline & AL3 & 180 & 425 & 211 & $8.5 \times 10^{-7}$ & $4.2 \times 10^{-6}$ \\
\hline & AL4 & 4680 & 3769 & 446 & $1.5 \times 10^{-4}$ & $1.8 \times 10^{-5}$ \\
\hline \multirow[t]{2}{*}{ Slag } & AL1 & 228 & 11.8 & 1.8 & $1.8 \times 10^{-7}$ & $2.8 \times 10^{-8}$ \\
\hline & AL2 & 314 & 6.3 & 0.53 & $7.1 \times 10^{-8}$ & $5.9 \times 10^{-8}$ \\
\hline \multirow[t]{2}{*}{ Secondary slag } & AL1 & 730 & 16.5 & 4.1 & $8.3 \times 10^{-7}$ & $2.1 \times 10^{-7}$ \\
\hline & AL2 & 980 & 4.5 & 0.24 & $1.6 \times 10^{-7}$ & $8.6 \times 10^{-8}$ \\
\hline
\end{tabular}

concentration of $6.5 \mathrm{pg}$ TEQ $\mathrm{m}^{-3}$. The concentration in the stack gas of the plant using clean scrap as the raw material was the lowest, i.e., $2.1 \mathrm{pg}$ TEQ $\mathrm{m}^{-3}$. The results of this study indicate that the use of dirty scrap may affect the emission levels of PCNs from stack gases. Dirty scrap may contain organic impurities such as plastics, paints, and solvents ( $2-15 \%$ by weight), which are sources of organic pollutants such as polyaromatic hydrocarbons (PAHs), and polychlorinated dibenzo-p-dioxins and dibenzofurans (PCDD/Fs) $[17,28,29]$. This might be an important factor in the higher emission concentrations of PCNs in stack gases from plants using dirty scrap as raw materials.

Among the plants that include dirty scrap in the raw materials, the TEQ concentration of PCNs in the stack gas of the plant using light oil as the fuel (AL1) was $69.8 \mathrm{pg} \mathrm{TEQ}^{-3}$; this was significantly higher than the average concentration for plants using natural gas as the fuel, which had an average value of $8.0 \mathrm{pg}^{\mathrm{T}} \mathrm{TEQ} \mathrm{m}^{-3}$. Similar trends were observed for the solid residues, i.e., fly ash, slag, and secondary slag. These results show that the emission levels of PCNs in discharges may be related to the fuel type. Studies have shown that incomplete combustion of fossil fuel causes polycyclic aromatic hydrocarbon pollution during multiple industrial processes [30,31]. Light oil (naphtha) is a fossil fuel composed mainly of alkanes, cycloalkanes, alkenes, and aromatic hydrocarbons with carbon numbers of 3-12. Natural gas and coal gas have higher combustion efficiencies, and their major components are methane, and carbon monoxide and hydrogen, respectively. The incomplete combustion of fossil fuel such as light oil in the furnace may provide carbon sources such as polycyclic aromatic hydrocarbons for the formation of PCNs. On the basis of this field investigation, further laboratoryscale studies will be useful in the identification and confirmation of the factors affecting PCNs during smelting.

\subsection{Trends in concentration as smelting stage changes}

Previous studies have indicated that during industrial processes PCDD/F emissions change as the conditions change [32-37]. Studies on PCN emission variations in industrial processes are scarce. There are four main smelting stages during secondary aluminum production (FD/FS/RF/CS). Several furnaces usually operate simultaneously in most secondary aluminum smelting plants, and they share one APCD system. Among the four plants investigated in this study, two of the plants (AL1 and AL3) had one furnace in operation during our sampling period. One operating furnace makes it possible to examine the PCN emission variations during different smelting stages without interference from other furnaces that share the same APCD system. In this study, we observed the variations in PCN emissions during different smelting stages to obtain a thorough understanding of the formation mechanism of PCNs during smelting. From Fig. 1, it can be seen that for each plant, the PCN concentration varied at different smelting stages. AL1 and AL3 had the highest levels of PCN formation in the FD stage. Studies have indicated that PCDD/Fs can form during the unsteady state in industrial thermal processes [32,37]. At the FD stage, the raw materials melt as a result of fuel combustion. As mentioned before, organic impurities from aluminum scrap and fuel have been recog-

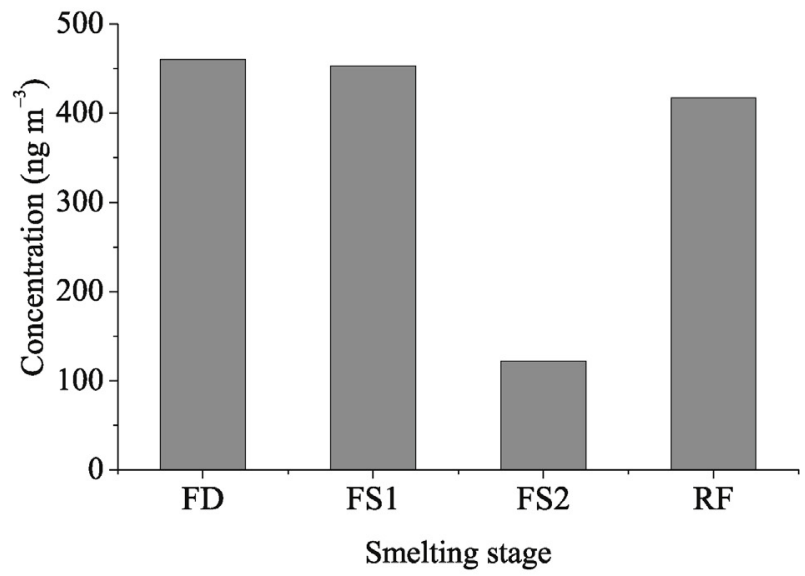

(a)

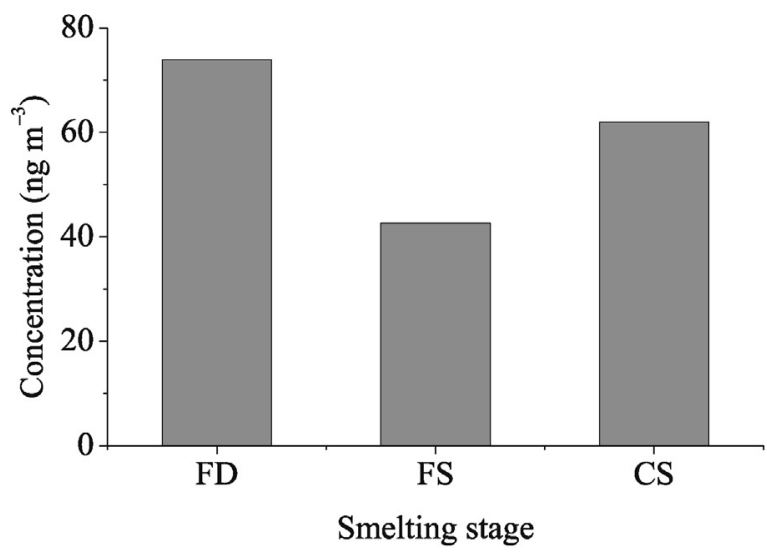

(b)

Fig. 1. Concentration of $\Sigma P C N$ from different smelting stages during secondary aluminum smelting: (a) plant AL1, (b) plant AL3. 


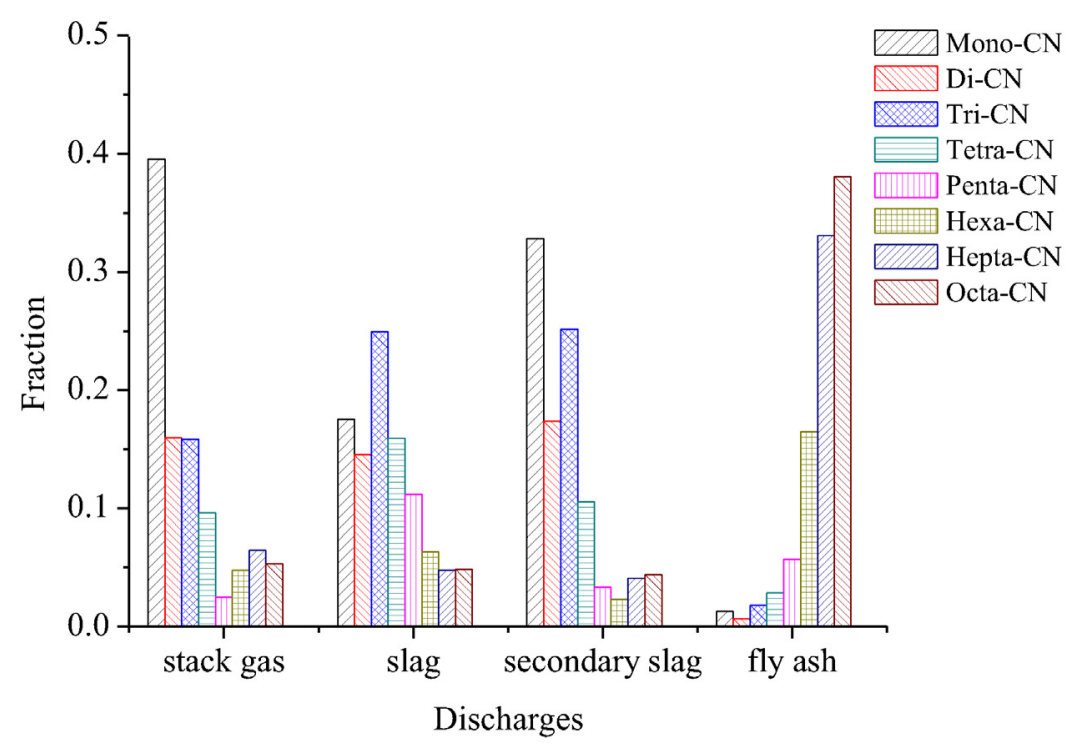

(a)

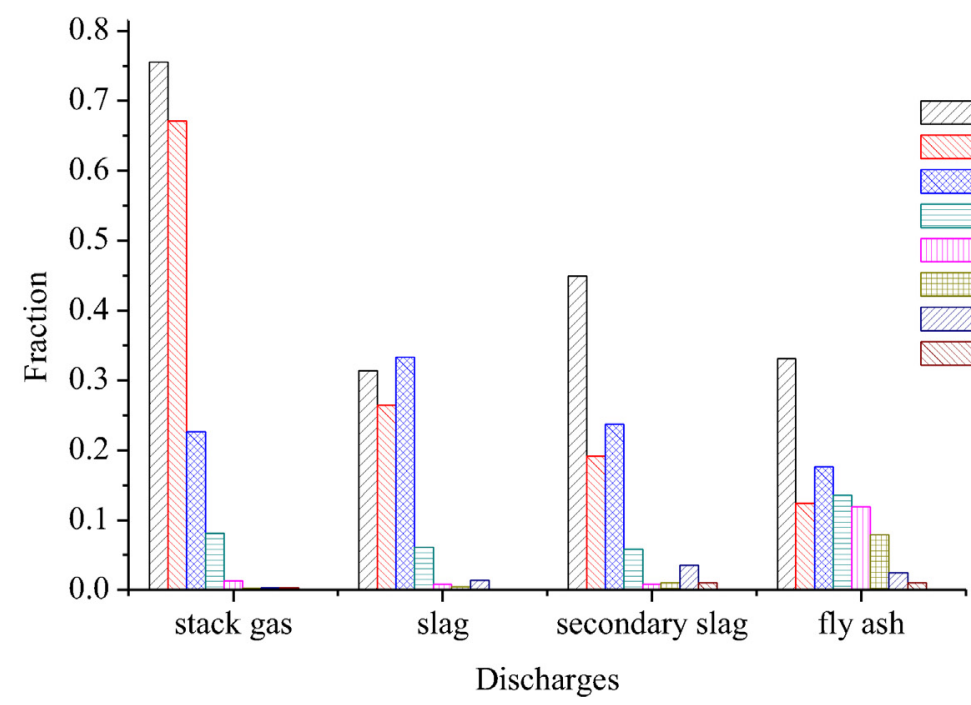

(b)

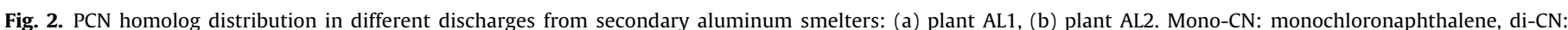

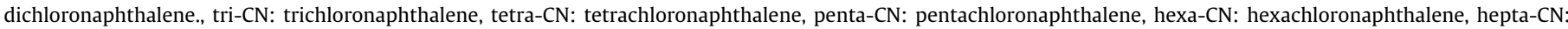
heptachloronaphthalene.

nized as aromatic hydrocarbon sources in the production of PCNs during secondary aluminum smelting. Moreover, the raw materials were added to the furnace in several batches, which may lead to unsteady conditions in the furnace during this stage. The combustion efficiency of the fuel or the organic impurities from the raw materials may therefore decrease under these unsteady operating conditions, and incomplete combustion may also occur, providing aromatic hydrocarbons for the production of PCNs.

In the subsequent FS stage, the PCN concentrations decreased in both plants. At this stage, some organic impurities in the raw materials may have been decomposed by heating, but some would still be present in the furnace, because of insufficient mixing. There was an increase in PCN emissions in the final stages (RF and CS) for AL1 and AL3. In AL1, the concentration in the RF stage was much higher than that in the previous stage (FS). During the RF stage, a flux, which usually consists of $\mathrm{NaCl}$ and $\mathrm{KCl}$, is added to remove some impurities from the molten aluminum. The enhancement in emis- sions in the RF stage may be attributable to chloride flux addition, as the chloride flux may act as a chlorine source for the formation of PCNs. In AL3, the PCN concentration also increased in the last stage, CS. During the CS stage, industrial talcum powder is used extensively for insulation of the molten aluminum. In the production of industrial talcum powder, $\mathrm{HCl}$ is used to remove raw talc impurities and is present in the products. It is therefore indicated that the intensive use of talcum powder may introduce $\mathrm{HCl}$ residues into the system; $\mathrm{HCl}$ was suggested to act as a chlorine source and promotes the formation of PCNs during the CS stage.

Based on this discussion, we suggest that variations in PCN emissions during the secondary aluminum smelting process may be related to variations in the feedstock composition at different smelting stages. High PCN emissions in the initial (FD) and final (RF and CS) stages of the smelting process were observed; this may be the result of incomplete combustion of organic impurities from the scrap and/or fuel, and the addition of chloride additives. 


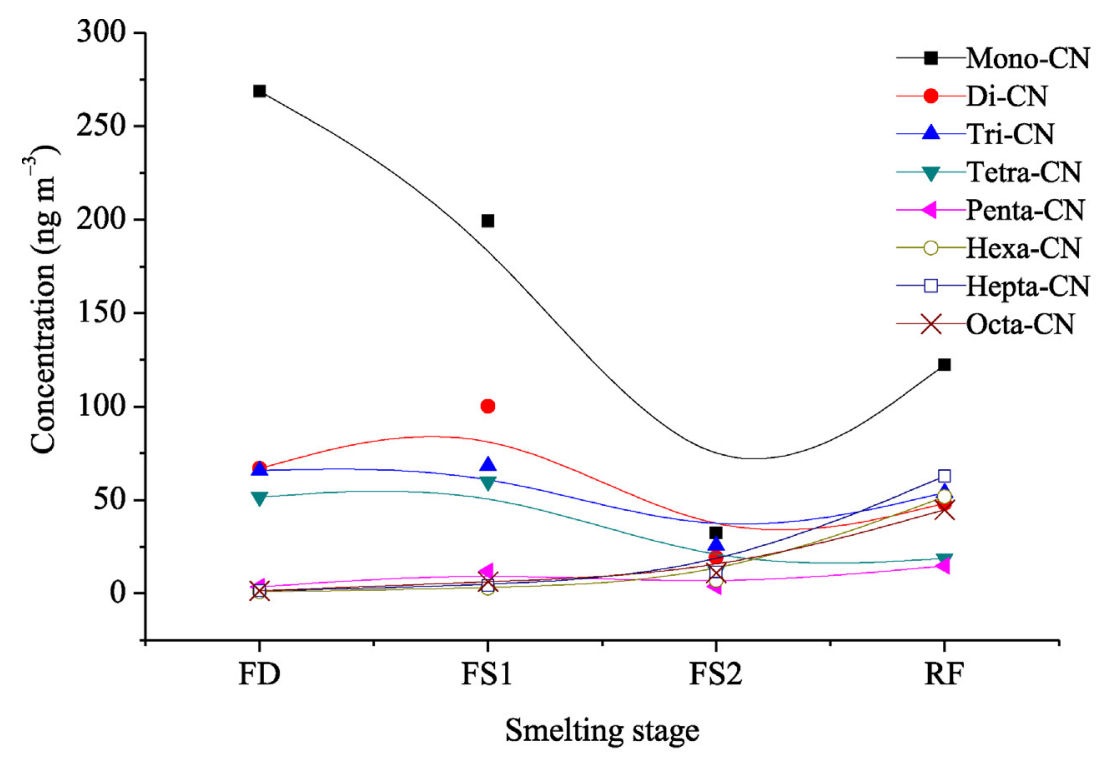

(a)

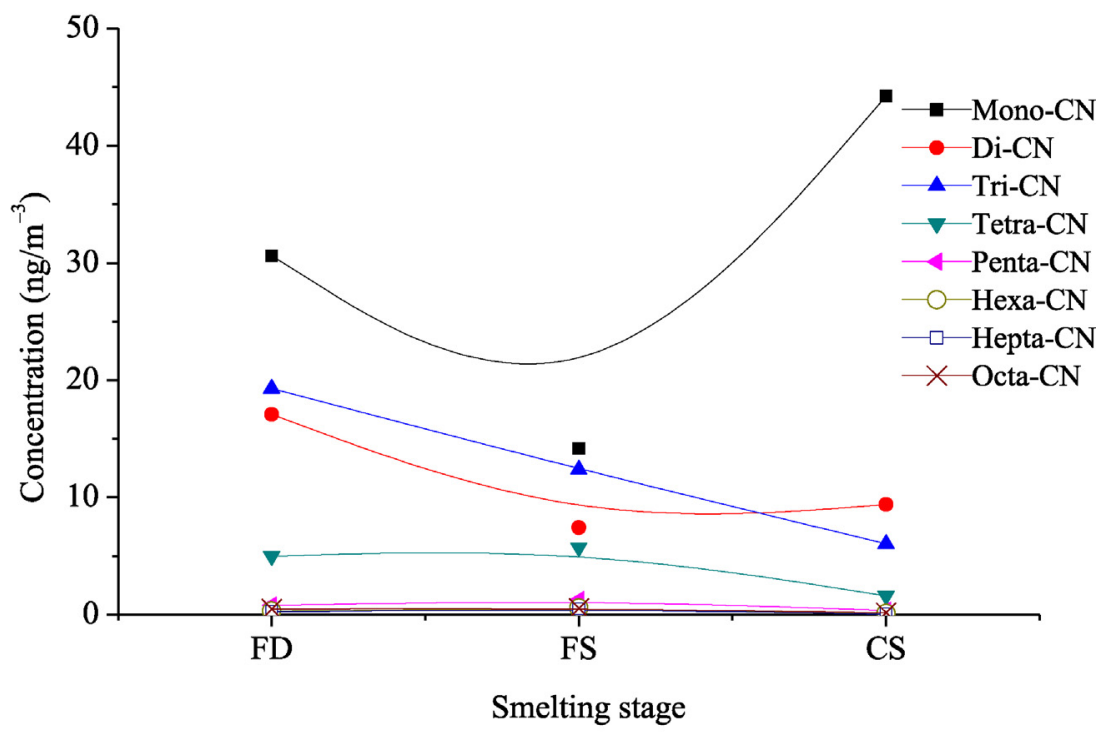

(b)

Fig. 3. Concentration of PCN homologs from different smelting stages during secondary aluminum smelting: (a) plant AL1, (b) plant AL3, mono-CN: monochloronaphthalene, di-CN: dichloronaphthalene, tri-CN: trichloronaphthalene, tetra-CN: tetrachloronaphthalene, penta-CN: pentachloronaphthalene, hexa-CN: hexachloronaphthalene, and hepta-CN: heptachloronaphthalene.

These results may provide useful information for developing operating technologies for the reduction of PCNs and other chlorinated organic pollutants from secondary aluminum smelting plants.

\subsection{Comparison of characteristics of PCNs from different discharges and during different smelting stages}

To observe the homolog changes in different types of discharges (stack gas, fly ash, slag, and secondary slag), the concentration of each homolog was expressed as a fraction of the total PCN (monoto octa-CN) concentration, as shown in Fig. 2. The homolog distributions of the four types of discharges from plants AL1 and AL2 are shown for a comprehensive and effective comparison. As can be seen from Fig. 2, the normalized distributions of homologs in the slag and secondary slag show a similar pattern to that in the stack gas, with mono- to tetra-homologs dominating. How- ever, the fractions of more-chlorinated homologs in the slag were higher than those in the stack gas. For fly ash, the distinction was more obvious. In particular, for AL1, the dominant homolog in the fly ash was octa-CN. More-chlorinated congeners, with high densities and high boiling points, tend to partition into particles, whereas less-chlorinated congeners and more-chlorinated naphthalenes are more likely to bind to the gas phase. It is therefore reasonable that mono- to tetra-CNs dominated the total PCNs in the stack gas samples of the two plants, whereas more-chlorinated naphthalenes were found in larger proportions in the solid residue samples, i.e., the slag, secondary slag, and fly ash.

The characteristics of the PCNs from different smelting stages were investigated to achieve a better understanding of the formation mechanism of PCNs emitted in secondary aluminum production. Fig. 3 shows the PCN homolog profiles of stack gas samples during different smelting stages in AL1 and AL3. As shown 
Table 3

Pearson coefficient between PCN homologs in PCN emissions from secondary aluminum smelting.

\begin{tabular}{|c|c|c|c|c|c|c|c|c|}
\hline & Mono-CN & $\mathrm{Di}-\mathrm{CN}$ & Tri-CN & Tetra-CN & Penta-CN & Hexa-CN & Hepta-CN & Octa-CN \\
\hline Mono- $\mathrm{CN}^{\mathrm{a}}$ & 1 & & & & & & & \\
\hline $\mathrm{Di}-\mathrm{CN}^{\mathrm{b}}$ & 0.113 & 1 & & & & & & \\
\hline Tri-CN ${ }^{c}$ & 0.152 & $0.845^{\mathrm{b}}$ & 1 & & & & & \\
\hline Tetra-CN ${ }^{d}$ & 0.163 & $0.563^{b}$ & $0.842^{\mathrm{b}}$ & 1 & & & & \\
\hline Penta-CN ${ }^{e}$ & -0.056 & $0.510^{\mathrm{a}}$ & $0.585^{\mathrm{b}}$ & $0.629^{b}$ & 1 & & & \\
\hline Hexa-CN ${ }^{f}$ & -0.164 & -0.177 & -0.142 & -0.131 & $0.521^{\mathrm{a}}$ & 1 & & \\
\hline Hepta-CN ${ }^{g}$ & -0.174 & -0.217 & -0.183 & -0.161 & $0.492^{\mathrm{a}}$ & $0.998^{\mathrm{b}}$ & 1 & \\
\hline Octa-CN ${ }^{h}$ & -0.191 & -0.238 & -0.208 & -0.167 & $0.498^{\mathrm{a}}$ & $0.989^{b}$ & $0.996^{\mathrm{b}}$ & 1 \\
\hline
\end{tabular}

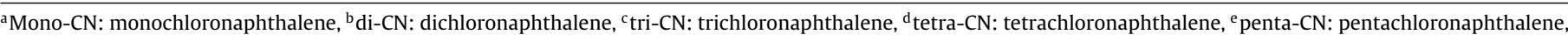

${ }^{f}$ hexa-CN: hexachloronaphthalene, ${ }^{g}$ hepta-CN: heptachloronaphthalene.

a Correlation is significant at the 0.05 level (2-tailed).

b Correlation is significant at the 0.01 level (2-tailed).

in Fig. 3, obvious variations in the homolog profile were observed for the two plants during different smelting stages. For AL1, the concentrations of mono-, di-, tri-, and tetra-CNs, which are lesschlorinated, clearly decreased from the FD to the FS stage, followed by an increase during the RF process. For the more-chlorinated penta- to octa-CN homologs, a slight increase in concentration was observed from the FD to the FS stage. The observed trend supports a chlorination mechanism from less- to more-chlorinated PCN homologs during these two stages. Unexpectedly, the concentrations of all homologs rose from the FS to the RF stage. It is suggested that incomplete combustion of the fuel or organic impurities from scrap might provide aromatic hydrocarbon sources, and the addition of chloride flux may provide a chlorine source for chlorination.

For plant AL3, a decrease in concentration from the FD to the FS stage, followed by an increase in the CS stage, was identified for the less-chlorinated homologs. The concentrations of morechlorinated homologs decreased slightly or stayed almost constant throughout the process, unlike the case for AL1. This difference may be the result of insufficient contact between the cast aluminum ingot and the talcum powder. Furthermore, the thermal conditions in the CS stage outside the furnace are not comparable to those inside the furnace during the RF stage. Chloride additives ( $\mathrm{HCl}$ impurities in talcum powder); therefore, facilitate the formation of less-chlorinated homologs from polycyclic aromatic hydrocarbons. However, chlorination from less- to morechlorinated homologs was not completed during the CS stage, and does not lead to obvious formation of more-chlorinated homologs. One sample was collected at each stage, because the duration of each stage within one production batch was not enough for parallel sample collection. This indicates the limitation of sample size in this study. However, it should be noted that the operating time of each stage during the investigated secondary aluminum smelting processes was approximately $2-4 \mathrm{~h}$ during a single smelting process. Use of the automatic isokinetic sampling system took about $2 \mathrm{~h}$, so only one stack gas sample was collected at each smelting stage. Because it was collected over almost the entire stage, we suggest that it is still representative of the process.

To further understand the mechanistic relationship between PCN homologs, the Pearson coefficient $(R)$ between each PCN homolog in all the stack gas samples was determined. It can be seen from Table 3 that adjacent PCN homolog groups are closely related to each other. This further supports the proposed hypothesis that chlorination is probably an important $\mathrm{PCN}$ formation pathway, similar to the study previously reported by Oh et al. [38], which showed that adjacent PCN homologs are closely related, and that the main PCN formation mechanisms probably involve chlorination and/or dechlorination.

\section{Conclusion}

Stack gas, fly ash, and slag samples were collected at different smelting stages from four secondary aluminum smelting plants. Large variations in PCN emission levels and homolog profiles during different smelting stages were observed. It was suggested that raw materials and fuels may provide sources of aromatic hydrocarbons for the production of PCNs; chloride additives such as chloride flux and talcum powder may provide chlorine sources for the formation of PCNs; the variations in these factors as the smelting stage changes may contribute to the variations in the PCN emission levels and homolog profiles. Correlation analysis and comparison of the homolog profiles suggested that chlorination from less-chlorinated homologs to more-chlorinated ones is an important pathway for PCN formation.

The PCN emission factors for gas-phase and solid-phase discharges were estimated. Stack gas was found to be the major contributor to the total PCN emissions. Among the solid-phase residues, fly ash was dominant in terms of PCN emissions. The characteristics of the homolog profiles of the slag, secondary slag, and fly ash were generally similar to those of the stack gas in each case plant, but larger fractions of higher-chlorinated homologs were observed in these solid residues. These results are helpful in gaining comprehensive information on PCN emission levels and distributions and in developing technologies and strategies for controlling unintentional PCN emissions in metallurgical processes.

\section{Acknowledgments}

We gratefully acknowledge support from the National 973 Program (2015CB453100), National Natural Science Foundation of China $(21477147,21477150)$, and Chinese Academy of Sciences (YSW2013A01).

\section{References}

[1] H. Park, J.H. Kang, S.Y. Baek, Y.S. Chang, Relative importance of polychlorinated naphthalenes compared to dioxins, and polychlorinated biphenyls in human serum from Korea: contribution to TEQs and potentia sources, Environ. Pollut. 158 (2010) 1420-1427.

[2] K. Kannan, T. Imagawa, A.L. Blankenship, J.P. Giesy, Isomer-specific analysis and toxic evaluation of polychlorinated naphthalenes in soil sediment, and biota collected near the site of a former chlor-alkali plant, Environ. Sci. Technol. 32 (1998) 2507-2514.

[3] K. Kannan, J.L. Kober, Y.S. Kang, S. Masunaga, J. Nakanishi, A. Ostaszewski, J.P. Giesy, Polychlorinated naphthalenes biphenyls, dibenzo-p-dioxins, and dibenzofurans as well as polycyclic aromatic hydrocarbons and alkylphenols in sediment from the Detroit and Rouge Rivers, Michigan, USA, Environ. Toxicol. Chem. 20 (2001) 1878-1889.

[4] J. Falandysz, Polychlorinated naphthalenes: an environmental update, Environ. Pollut. 101 (1998) 77-90.

[5] N. Yamashita, K. Kannan, T. Imagawa, A. Miyazaki, J.P. Giesy, Concentrations and profiles of polychlorinated naphthalene congeners in eighteen technical 
polychlorinated biphenyl preparations, Environ. Sci. Technol. 34 (2000) 4236-4241.

[6] G.R. Liu, Z.W. Cai, M.H. Zheng, Sources of unintentionally produced polychlorinated naphthalenes, Chemosphere 94 (2014) 1-12.

[7] E. Abad, J. Caixach, J. Rivera, Dioxin like compounds from municipal waste incinerator emissions: assessment of the presence of polychlorinated naphthalenes, Chemosphere 38 (1999) 109-120.

[8] T. Takasuga, T. Inoue, E. Ohi, K.S. Kumar, Formation of polychlorinated naphthalenes dibenzo-p-dioxins, dibenzofurans, biphenyls, and organochlorine pesticides in thermal processes and their occurrence in ambient air, Arch. Environ. Con. Tox. 46 (2004) 419-431.

[9] T. Ba, M.H. Zheng, B. Zhang, W.B. Liu, G.J. Su, G.R. Liu, K. Xiao, Estimation and congener-specific characterization of polychlorinated naphthalene emissions from secondary nonferrous metallurgical facilities in China, Environ. Sci. Technol. 44 (2010) 2441-2446.

[10] G.R. Liu, M.H. Zheng, B. Du, Z.Q. Nie, B. Zhang, J.C. Hu, K. Xiao, Identification and characterization of the atmospheric emission of polychlorinated naphthalenes from electric arc furnaces, Environ. Sci. Pollut. Res. 19 (2012) 3645-3650.

[11] G.R. Liu, M.H. Zheng, B. Du, Z.Q. Nie, B. Zhang, W.B. Liu, C. Li, J.C. Hu, Atmospheric emission of polychlorinated naphthalenes from iron ore sintering processes, Chemosphere 89 (2012) 467-472.

[12] A. Kaune, K.-W. Schramm, R. Lehnardt, A. Kettrup, I. Ollenschläger, H. Rossel, Polychlorinated dibenzodioxins and dibenzofurans in the aluminium recycling process, J. Anal. Appl. Pyrol. 49 (1999) 191-198.

[13] G. Laue, D. Herrmann, M. Möder, R. Herzschuh, Analysis of slags and filter dusts from aluminum recycling processes, Chemosphere 29 (1994) 1947-1956.

[14] Z. Nie, M. Zheng, W. Liu, B. Zhang, G. Liu, G. Su, P. Lv, K. Xiao, Estimation and characterization of PCDD/Fs, dl-PCBs, PCNs, $\mathrm{H} \times \mathrm{CBz}$ and $\mathrm{PeCBz}$ emissions from magnesium metallurgy facilities in China, Chemosphere 85 (2011) 1707-1712.

[15] S. Sinkkonen, J. Paasivirta, M. Lahtipera, A. Vattulainen, Screening of halogenated aromatic compounds in some raw material lots for an aluminium recycling plant, Environ. Int. 30 (2004) 363-366.

[16] G. Laue, D. Herrmann, M. Moder, R. Herzschuh, Analysis of slags and filter dists from aluminum recycling processes, Chemosphere 29 (1994) 1947-1956.

[17] Y.H. Wang, C. Lin, Y.C. Lai, G.P. Chang-Chien, Characterization of PCDD/Fs PAHs, and heavy metals in a secondary aluminum smelter, J. Environ. Sci. Health A 44 (2009) 1335-1342.

[18] J.P. Aittola, J. Paasivirta, A. Vattulainen, S. Sinkkonen, J. Koistinen, J. Tarhanen, Formation of chloroaromatics at a metal reclamation plant and efficiency of stack filter in their removal from emission, Chemosphere 32 (1996) 99-108

[19] G.R. Liu, M.H. Zheng, P. Lv, W.B. Liu, C.Z. Wang, B. Zhang, K. Xiao, Estimation and characterization of polychlorinated naphthalene emission from coking industries, Environ. Sci. Technol. 44 (2010) 8156-8161.

[20] A.L. Blankenship, K. Kannan, S.A. Villalobos, D.L. Villeneuve, J. Falandysz, T. Imagawa, E. Jakobsson, J.P. Giesy, Relative potencies of individual polychlorinated naphthalenes and halowax mixtures to induce $\mathrm{Ah}$ receptor-mediated responses, Environ. Sci. Technol. 34 (2000) 3153-3158.

[21] D.L. Villeneuve, K. Kannan, J.S. Khim, J. Falandysz, V.A. Nikiforov, A.L. Blankenship, J.P. Giesy, Relative potencies of individual polychlorinated naphthalenes to induce dioxin-like responses in fish and mammalian in vitro bioassays, Arch. Environ. Contamin. Toxicol. 39 (2000) 273-281.
[22] A. Hanberg, F. Waern, L. Asplund, E. Haglund, S. Safe, Swedish dioxin survey determination of 2,3,7,8-Tcdd toxic equivalent factors for some polychlorinated-biphenyls and naphthalenes using biological tests, Chemosphere 20 (1990) 1161-1164.

[23] P.A. Behnisch, K. Hosoe, S. Sakai, Brominated dioxin-like compounds: in vitro assessment in comparison to classical dioxin-like compounds and other polyaromatic compounds, Environ. Int. 29 (2003) 861-877.

[24] K. Kannan, N. Yamashita, T. Imagawa, W. Decoen, J.S. Khim, R.M. Day, C.L. Summer, J.P. Giesy, Polychlorinated naphthalenes and polychlorinated biphenyls in fishes from Michigan waters including the Great Lakes, Environ. Sci. Technol. 34 (2000) 566-572.

[25] J. Falandysz, A. Fernandes, E. Gregoraszczuk, M. Rose, Aryl hydrocarbon receptor mediated (dioxin-like) relative potency factors for Chloronaphthalenes Organohalogen Compd. 75 (2013) 336-338.

[26] Y. Noma, T. Yamamoto, S.I. Sakai, Congener-specific composition of polychlorinated naphthalenes coplanar PCBs, dibenzo-p-dioxins, and dibenzofurans in the halowax series, Environ. Sci. Technol. 38 (2004) 1675-1680.

[27] G.R. Liu, M.H. Zheng, W.B. Liu, C.Z. Wang, B. Zhang, L.R. Gao, G.J. Su, K. Xiao, P. Lv, Atmospheric emission of PCDD/Fs, PCBs, hexachlorobenzene, and pentachlorobenzene from the coking industry, Environ. Sci. Technol. 43 (2009) 9196-9201.

[28] C. Zhang, X. Ni, H. Ouyang, C. Lu, On dioxins formed during recycling of waste aluminum, Shanghai Nonferrous Met. 29 (2008) 63-68 (In Chinese).

[29] China's MEP, Instructions for emmission standard of pollutants for secondary nonferrous metal industry, 2014. (In Chinese).

[30] H.H. Yang, W.J. Lee, S.J. Chen, S.O. Lai, PAH emission from various industrial stacks, J. Hazard. Mater. 60 (1998) 159-174.

[31] L. Mu, L. Peng, J. Cao, Q. He, F. Li, J. Zhang, X. Liu, H. Bai, Emissions of polycyclic aromatic hydrocarbons from coking industries in China, Particuology 11 (2013) 86-93.

[32] C.-S. Chyang, Y.-L. Han, L.-W. Wu, H.-P. Wan, H.-T. Lee, Y.-H. Chang, An investigation on pollutant emissions from co-firing of RDF and coal, Waste Manage. 30 (2010) 1334-1340.

[33] B.K. Gullett, W.P. Linak, A. Touati, S.J. Wasson, S. Gatica, C.J. King, Characterization of air emissions and residual ash from open burning of electronic wastes during simulated rudimentary recycling operations, $\mathrm{J}$. Mater. Cycl. Waste Manage. 9 (2007) 69-79.

[34] J.C. Hu, M.H. Zheng, Z.Q. Nie, W.B. Liu, G.R. Liu, B. Zhang, K. Xiao, Polychlorinated dibenzo-p-dioxin and dibenzofuran and polychlorinated biphenyl emissions from different smelting stages in secondary copper metallurgy, Chemosphere 90 (2013) 89-94.

[35] K.H. Karstensen, Formation, release and control of dioxins in cement kilns, Chemosphere 70 (2008) 543-560.

[36] E. Kasai, Y. Hosotani, T. Kawaguchi, K. Nushiro, T. Aono, Effect of additives on the dioxins emissions in the iron ore sintering process, ISIJ Int. 41 (2001) 93-97.

[37] B. Wyrzykowska-Ceradini, B.K. Gullett, D. Tabor, A. Touati, PBDDs/Fs and PCDDs/Fs in the raw and clean flue gas during steady state and transient operation of a municipal waste combustor, Environ. Sci. Technol. 45 (2011) 5853-5860.

[38] J.-E. Oh, B. Gullett, S. Ryan, A. Touati, Mechanistic relationships among PCDDs/Fs, PCNs, PAHs, CIPhs, and CIBzs in municipal waste incineration, Environ. Sci. Technol. 41 (2007) 4705-4710. 